\title{
Double blind study of ispaghula in irritable bowel syndrome
}

\author{
ALISON PRIOR AND P J WHORWELL \\ From the Dept of Medicine, University Hospital of South Manchester, Manchester
}

SUMmary A double blind placebo controlled trial of ispaghula husk in 80 patients with irritable bowel syndrome is reported. Global assessment judged treatment to be satisfactory in $82 \%$ of patients receiving ispaghula and $53 \%$ of the placebo group $(\mathrm{p}<0 \cdot() 2)$. Bowel habit was unchanged in the placebo group, while constipation significantly improved in patients taking ispaghula $(\mathrm{p}=0 \cdot() 26)$. Transit time decreased significantly in those taking ispaghula compared with placebo $(p=0 \cdot(0) 1)$, especially in patients with initially high transit times. Abdominal pain and bloating improved in both groups, with no significant differences between ispaghula and placebo. Four of the eight withdrawals on ispaghula and 10 of the 15 withdrawals on placebo were because of treatment failure. Ispaghula significantly improves overall well being in patients with irritable bowel syndrome, and in those with constipation favourably affects bowel habit and transit time.

Bulking agents are often recommended as part of the initial management of irritable bowel syndrome (IBS).' - Although there is some evidence from controlled trials confirming their efficacy, ${ }^{34}$ the majority of studies have failed to show an effect greater than placebo. ${ }^{-1 "}$ One explanation for these differences is that they relate to variations in study design, and in particular past studies have often only involved small numbers of patients followed up for relatively short periods of time. Additionally response to therapy has often been judged by a sense of wellbeing rather than assessment of the effect on individual symptoms of IBS. We report a double blind controlled trial of therapy with ispaghula husk over a three month period in patients with irritable bowel syndrome.

\section{Methods}

PATIENTS

Eighty consecutive patients with IBS (72 women, eight men, age range $18-63$ years) were recruited

\footnotetext{
Address for correspondence: Dr P J Whorwell. Department of Medicine. University Hospital of South Manchester. Nell Iane. West Didsbury. Manchester M?(I) SI.R.

Reccived for publication 15 April 1987.
}

from the outpatient department. Diagnosis of IBS was based on the presence of abdominal discomfort and abdominal distension together with an abnormal bowel habit. Bowel habit abnormalities were classified as frequent defecation (three or more mushy stools per day - seven patients), constipation (less than three stools per week together with straining at stool - 39 patients) or alternating frequent defecation and constipation -34 patients.

All patients had normal haematology, biochemistry, sigmoidoscopy, and in those over 40 years contrast radiology or colonoscopy. After a two week baseline period the patients were then randomised to treatment with either flavoured ispaghula husk (Regulan) or placebo (the exipients of Regulan without the ispaghula husk). A dose of one sachet of Regulan $(6 \cdot 4 \mathrm{~g}$ rough ground powder containing $3.6 \mathrm{~g}$ refined active mucilloid $-56 \%$ ispaghula) or placebo three times daily was initially recommended. Patients were given an option to change the dose depending on response, so that if their bowel habit improved but did not normalise they were advised to try a slight increase in dose, if unacceptable loosening of stools occurred it was suggested that the dose was decreased.

Throughout the study patients entered details of their bowel habit and the severity and frequency of abdominal pain, and bloating on daily diary cards 
with follow up visits at four, eight, and 12 weeks of treatment. Overall improvement in wellbeing was assessed after discussion with patients and treatment judged as being satisfactory if they felt generally better, but unsatisfactory if they felt worse or unchanged. A dietary assessment and measurement of transit time was done at the beginning and end of the study. Whole gut transit times were assessed using a carmine marker technique "in which patients ingested $720 \mathrm{mg}$ dye at 9 am on the study day and recorded the time at which their stools first became discoloured.

Results were analysed on an intent to treat basis so that if a subject withdrew from the study the last available data were used in the final analysis. All significance tests done were two sided and were carried out at the $5 \%$ level. Diary card data were analysed using an analysis of covariance and the assessment of overall progress analysed using Fisher's exact test.

\section{Results}

There was no significant difference between the ispaghula and placebo groups in terms of severity of symptoms and type of bowel disturbance.

A total of 57 patients completed the trial. Four of the eight withdrawals from the ispaghula group and 10 of the 15 placebo withdrawals were because of treatment failure $(p=N S)$. There were five withdrawals because of non-compliance, two because of the development of conditions requiring gynaecological intervention and two patients lost to follow up. Of the withdrawals because of treatment failure in the placebo group, one occurred at three weeks, 11 between four and eight weeks, and three between eight and 12 weeks. In the ispaghula treated group six patients withdrew between four and eight weeks and two between eight and 12 weeks. Both the ispaghula and placebo were well tolerated by patients with only one withdrawal from each group related to possible side effects (flatulence on ispaghula, nausea on placebo). Of the four patients with frequent defecation treated with ispaghula none noted an increase in stool frequency, although two patients with an alternating bowel habit developed troublesome loose stools. No exacerbation of distension or pain occurred while on ispaghula although one patient complained of increased flatulence.

Patients in the placebo group tended to use more sachets than those taking ispaghula (at 12 weeks $71 \%$ in placebo and $50 \%$ in ispaghula group taking three or more per day). Dietary assessment revealed an overall mean intake of $12.3 \mathrm{~g}$ dietary fibre before the study (range 2-26 g). During treatment there was a tendency for those on placebo to increase their fibre intake (from $11.3 \mathrm{~g}-14.2 \mathrm{~g}$ ) but this was considerably less than the total fibre intake of the patients taking ispaghula ( $11.3 \mathrm{~g}$ from diet $+10.9 \mathrm{~g}$ from ispaghula ).

The results of the study are summarised in Tables 1 and 2. Table 1 shows that global assessment judged treatment to be satisfactory in $82 \%$ of the ispaghula group compared with $53 \%$ of the placebo group $(p<0 \cdot 02)$. The number of days with no bowel actions was decreased significantly in the ispaghula group compared with placebo $(p=0 .(226)$ but little change in the number of days with three or more bowel actions occurred in either treatment group. From Tables 1 and 2 it is clear that both the frequency and severity of pain and distension decreased in both groups during the course of the study with no significant advantage for ispaghula. Analysis of results with regard to dietary fibre revealed that response to treatment was not dependent on the initial level of intake.

The figure shows the change in transit time with treatment. Before treatment the mean transit time in the ispaghula group was $36 \cdot 1$ hours and this decreased significantly during the study to 21.9 hours $(p=0 \cdot 001)$. The reduction in transit times was more marked in those subjects with initially high values. In the placebo group the prestudy mean transit time was $28 \cdot 8$ hours and at the end of the study had increased,

Table 1 Frequency of symptoms and overall efficacy of treatment

\begin{tabular}{|c|c|c|c|c|}
\hline \multirow[b]{2}{*}{ Symptoms } & \multirow[b]{2}{*}{ Treatment } & \multicolumn{2}{|c|}{ Days/weeks with symptoms } & \multirow{2}{*}{$\begin{array}{l}\text { Suatistical difference } \\
\text {-between treatment witl } \\
\text { ispaghula and placebo }\end{array}$} \\
\hline & & Pretreatment & End of study & \\
\hline \multirow[t]{2}{*}{ Nobowel actions } & Ispaghula & 1.7 & $1 \cdot()$ & \multirow[t]{2}{*}{$p=() \cdot(1) 26$} \\
\hline & Placcbo & $1 \cdot 8$ & 1.7 & \\
\hline \multirow{2}{*}{ Three of more bowel actions } & Ispaghula & 0.7 & 0.9 & \multirow[t]{2}{*}{ NS } \\
\hline & Placcbo & 0.5 & $(1) \cdot 6$ & \\
\hline Abdominal pain & Placcho & $4 \cdot()$ & $2 \cdot 8$ & NS \\
\hline \multirow[t]{2}{*}{ Bloating } & Ispaghula & $4 \cdot 1$ & 3.7 & \multirow[t]{2}{*}{ NS } \\
\hline & Placcbo & $4 \cdot()$ & $2 \cdot 7$ & \\
\hline \multirow{2}{*}{$\begin{array}{l}\text { Overall assessment of treatment } \\
\text { success }\end{array}$} & Ispaghula & & $82 \%$ & \multirow[t]{2}{*}{$p=0 \cdot() 2$} \\
\hline & Placcbo & & $5.3 \%$ & \\
\hline
\end{tabular}


Table 2 Change in severity of pain and bloating during study period

\begin{tabular}{|c|c|c|c|c|c|c|c|c|}
\hline \multirow{3}{*}{$\begin{array}{l}\text { Symptom } \\
\text { severity }\end{array}$} & \multicolumn{4}{|c|}{ Abdominal pain } & \multicolumn{4}{|l|}{ Bloating } \\
\hline & \multicolumn{2}{|l|}{ Ispaghula } & \multicolumn{2}{|l|}{ Placebo } & \multicolumn{2}{|l|}{ Ispaghula } & \multicolumn{2}{|l|}{ Placebo } \\
\hline & Pretreatment & Endstudy & Pretreatment & Endstudy & Pretreatment & Endstudy & Pretreatment & End study \\
\hline Absent & 0 & 7 & () & 3 & 0 & 0 & 0 & 7 \\
\hline Mild & 3 & 14 & 2 & 20 & 4 & 3 & 3 & 16 \\
\hline Severe & 10 & 3 & 9 & 1 & 16 & 15 & 15 & 6 \\
\hline
\end{tabular}

but not significantly, to $39 \cdot 8$ hours. The difference between the initial mean transit times in the two groups was not significant $(p=() \cdot 28)$.

\section{Discussion}

This study shows that when treated with ispaghula patients with IBS appear to feel better than those receiving placebo $(p<0 \cdot 02)$ irrespective of initial bowel habit. In addition ispaghula proved useful in relieving constipation as measured both by a decrease in the number of days with no bowel action $(p=0.026)$ and by an improvement in transit times $(p=0 \cdot 001)$. With respect to abdominal pain and distension, however, improvement was noted in both the placebo and ispaghula treated groups with no significant differences between the two.

It is therefore of interest to ask why ispaghula

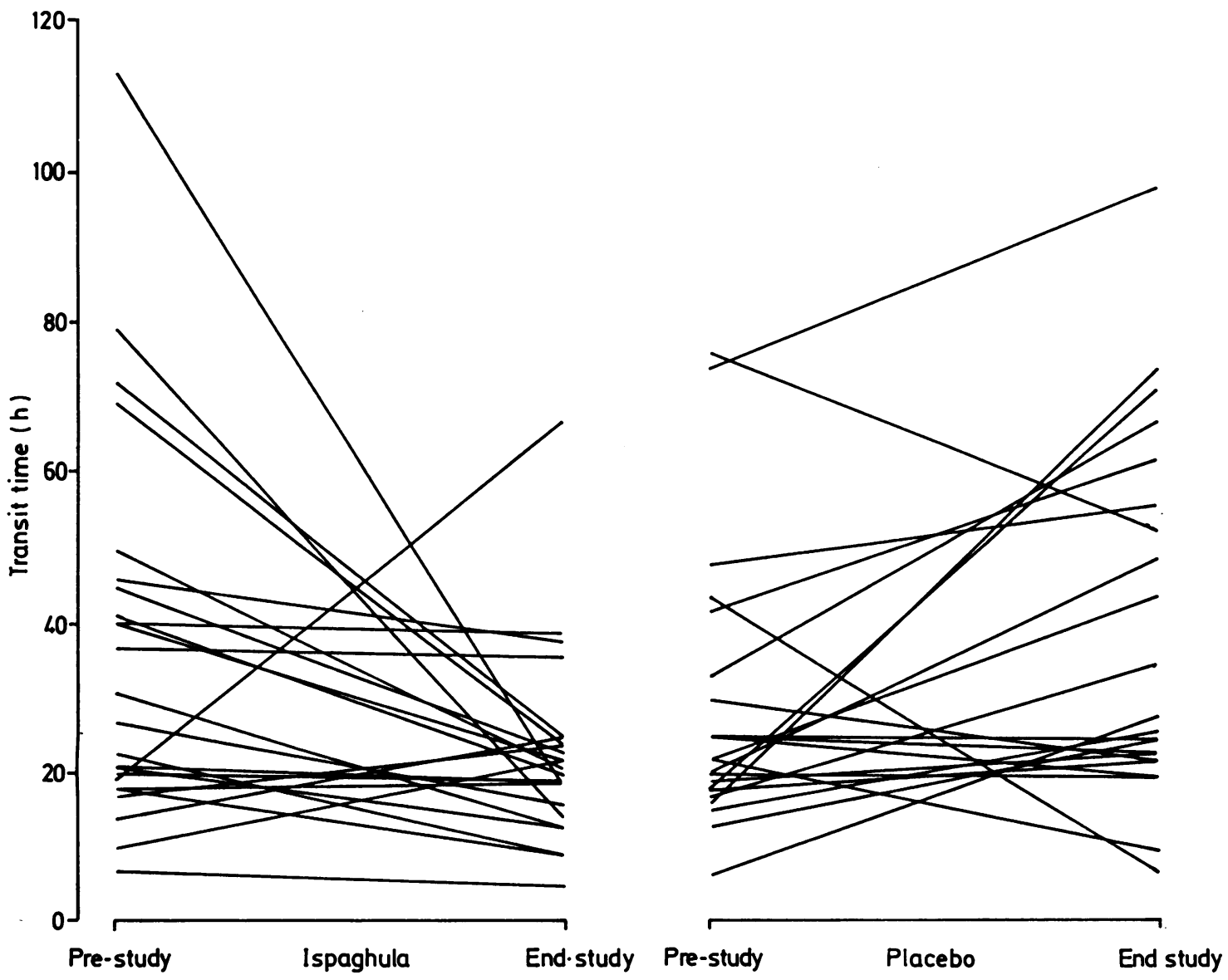

Figure Changes in transit time with treatment 
should have an additional advantage over placebo in terms of improved well being. As a large proportion of the patients were constipated it was considered possible that the improvement in overall wellbeing was reflecting a response in this particular subgroup. When the constipated patients were analysed separately, however, although a significant improvement in bowel habit occurred when taking ispaghula, a similiar improvement in abdominal pain and distension was noted on placebo and active treatment. The improvement in wellbeing was also not simply reflecting the change in bowel habit as it was seen in similar proportions of patients in all subgroups treated with ispaghula (18/21 constipated patients with improved wellbeing $v 15 / 19$ non-constipated patients). It may be therefore that ispaghula therapy was associated with an improvement of other symptoms now recognised to be frequently associated with IBS, ${ }^{12}$ but which were not recorded in the present study.

It has been argued that the aim of treatment in IBS should be overall symptomatic improvement rather than the elimination of individual symptoms ${ }^{+}$and to date many previous trials investigating the use of therapeutic agents in IBS have used only a subjective improvement in wellbeing as the measure of efficacy. ${ }^{\prime 2}$ As no one drug has been shown to benefit all the symptoms of IBS, however, it is only by examining the change in individual symptoms that indications for particular forms of treatment will be clearly delineated.

Previous studies investigating the efficacy of bulking agents in IBS have largely revealed disappointing results. ${ }^{-111}$ Of those examining individual symptoms only one has shown an improvement in abdominal pain" although its findings have been questioned in view of the lack of placebo response noted in patients receiving a control diet. ${ }^{14}$ An improvement in constipation alone similar to that noted in the present study has been observed in one open, "and one controlled"' trial of bran. It has been suggested that the lack of response of other symptoms to bulking agents might be partially related to the relatively short time for which treatment was given" although this is not supported by our findings. It is noteworthy that the placebo response was maintained over the 12 weeks of observation.

In conclusion, the results of this study suggest that ispaghula is useful in relieving constipation and improving wellbeing in patients with IBS, but is no more effective than placebo in relieving abdominal pain and distension.

This material was presented at the Spring meeting of the British Society of Gastroenterology, Lancaster, 1986. We thank Mr P D Wilkinson for performing the statistical analysis.

\section{References}

1 Fielding JR. The irritable bowel syndrome. Clin Gastroenterol 1977: 6: 622 .

2 Thompson WG. The irritable bowel. Gut 1984; 25: 3()5-20.

3 Manning AP, Heaton KW, Harvey RF, Uglow P. Wheat fibre and irritable bowel syndrome a controlled trial. Lancet 1977; ii: 417-18.

4 Ritchie JA. Truelove SC. Treatment of irritable bowel syndrome with lorazepam, hyoscine butylbromide and ispaghula husk. $\mathrm{Br}$ Med J 1979; i: 376-8.

5 Soltoft J, Gudmand-Hoyer E. Krag B, Kristensen E. Wulff HR. A double blind trial of the effect of wheat bran on the symptoms of irritable bowel syndrome. Lancet 1976; i: 27()-2.

6 Longstreth GF, Fox DD, Youkeles L. Forsythe AB, Wolochow DA. Psyllium therapy in the irritable bowel syndrome. A double blind trial. Ann Intern Med 1981: 95: 53-6.

7 Arthurs Y. Fielding JF. Double blind trial of ispaghula/ poloxamer in the irritable bowel syndrome. Ir Med $J$ 1983; 76: 253.

8 Cann PA, Read NW, Holdsworth CD. What is the benefit of coarse wheat bran in patients with irritable bowel syndrome. Gut 1984; 25 : 168-73.

9 Lucey MR, Clark ML, Lowndes J, Dawson AM. Is bran efficacious in irritable bowel syndrome? [Abstract]. Gut 1984; 25: A.583.

10 Arffman S, Andersen JR, Hegnhoj J, et al. The effect of coarse wheat bran in the irritable bowel syndrome. A double blind cross over study. Scand J Gastroenterol 1985; 20: 295-8.

11 Hinton JM, Lennard-Jones JE, Young AC. A new method for studying gut transit times using radioopaque markers. Gut 1969; 10: 842-7.

12 Whorwell PJ, McCallum M, Creed FH, Roberts CT. Non-colonic features of irritable bowel syndrome. Gut 1986; 27 : 37-40.

13 Holdsworth CD. Drug treatment of irritable bowel syndrome. In: Read NW, ed. Irritable bowel syndrome. New York: Grune and Stratton, 1985: 223-32.

14 Heaton KW. Role of dietary fibre in irritable bowel syndrome. In: Read NW, ed. Irritable bowel syndrome. New York: Grune and Stratton 1985: 203-22. 